\title{
Hydrogen Peroxide vs Liquid Methane: Green Bipropellants for Future Space Propulsion Applications
}

\author{
S. Gorakula ${ }^{1}$, M.S.R. Bondugula ${ }^{2}$, S. Patel ${ }^{3 *}$, A. Inapanury ${ }^{4}$ \\ ${ }^{1}$ Aeronautical Engineering, Politecnico di Milano, Milan, Italy \\ ${ }^{2}$ Space Engineering, Politecnico di Milano, Milan, Italy \\ 3* Aerospace Engineering, IIAEM, Jain (Deemed-to-be University), Bangalore, India \\ ${ }^{4}$ Aerospace Engineering, Alma mater Studiorum - Universita di Bologna, Forli, Italy
}

DOI: 10.29322/IJSRP.11.08.2021.p11643

http://dx.doi.org/10.29322/IJSRP.11.08.2021.p11643

\begin{abstract}
Recent space developments are implementing several simpler and less expensive rocket technologies. Environmental concerns and following governmental restrictions necessitate to replace current (hydrazine-based) toxic propellants with green ones, with a minimum loss of performance. Hydrogen peroxide is a promising candidate for the future of green propellants due to its flexibility and its benign nature allows the advancement of simple, cost-effective, and environmentally friendly propulsion with sufficient performance to replace hydrazine or other highperforming toxic propellants. Consequently, this thesis is devoted for the study of hydrogen peroxide-based propellants for future space propulsion applications. The main objective of this work is to study the combustion properties of green propellants. Foremost we discussed the hydrogen peroxide use, properties, and management of in-space propulsion, and later, various combinations and compositions with hydrogen peroxide as a bipropellant have been studied using NASA CEA code. The main purpose is to find combustion temperature and specific impulse values at different $\mathrm{O} / \mathrm{F}$ ratios of $2,4,6,8,10$ and various pressure chamber values of 20,25, and 30 bar. For this purpose, two cases have been considered to study the bi propellant of liquid methane and mass fraction variation is obtained at different $\mathrm{O} / \mathrm{F}$ ratio and at chamber, throat and exit. Analysis has done considering all the compositions and comparison of combustion products in the case of bi propellant in order to achieve the best efficiency at proper $\mathrm{O} / \mathrm{F}$ ratio and fixed chamber pressure. It is observed that concentration of hydrogen peroxide has the significant effect on combustion performances and the chemical composition effects due to weight concentration. It is concluded that hydrogen peroxide is useful for the future development of the research activity.
\end{abstract}

Index Terms- Green Propellants; Hydrogen Peroxide; Bipropellant; Liquid Methane; Space Propulsion; CEA Analysis

\section{INTRODUCTION}

$\mathrm{T}_{\mathrm{h}}$ he use of green propellants promises benefits in terms of

overall life cycle cost reduction, lowering the cost of access to space, and reducing environmental impact. The term "Green Propellant" refers to a family of propellants, whether liquid, solid, hybrid, mono- or bi- propellant, that meet criteria such as low toxicity, low pollution impact, good storability, broad material compatibility, and good performance [1]. Green propellants are low-toxicity, high- energy liquid rocket propellants that will provide future spacecraft with a highperformance, high-efficiency alternative to conventional chemical propellants. Hydrazine is a dangerously unstable and highly toxic substance. Importantly, its use as a propellant has been restricted by strict legislation designed to protect workers who work with extremely toxic and carcinogenic substances [1]. Hydrogen peroxide $(\mathrm{H} 2 \mathrm{O} 2)$ is one of the most desirable alternatives, not only because it is non-toxic and noncarcinogenic, but also because of its many benefits, including its high density and low cost. $\mathrm{H} 2 \mathrm{O} 2$ also offers substantial cost savings due to the dramatic simplifications in health and safety security procedures during the propellant's processing, storage, and handling. In this paper, hydrogen peroxide was investigated as a bipropellant with liquid methane using the CEA code, and its use in future space propulsion applications was discussed. The most promising characteristics of green propellants that seek to minimize costs, complexity, and pollution [1] are its low toxicity, low pollution impact, low cost and performances.

\section{A GREEN, CHEAP AND EFFECTIVE PROPELLANT: HYDROGEN PEROXIDE}

The chemical compound hydrogen peroxide has the formula $(\mathrm{H} 2 \mathrm{O} 2)$. It is a colorless liquid that is slightly more viscous than water in its pure form. Hydrogen peroxide is a powerful oxidizer that is used as a bleaching and disinfectant. Since 1934, concentrated hydrogen peroxide, also known as 'high-test peroxide' (HTP), has been used as a rocket propellant. HTP is currently used on the Soyuz Launcher for the first stage gas generator and the Soyuz capsule for the reaction control thrusters used during re-entry. The manufacturing and transport of 98 percent were qualified within the framework of the $\mathrm{H}_{2} \mathrm{O}_{2}$ project HYPROGEO, and this propellant blend is now commercially available on the market [2]. Hydrogen Peroxide was studied at ASL in the context of a fully ALM printed thruster [3], and it is now regarded as a low-cost option for orbital propulsion. When compared to traditional Hydrazine, it has the following advantages such as non-toxic, non-carcinogenic, cheap, 
commercially available, cold-start capable, low decomposition temperature $\left(<1000^{\circ} \mathrm{C}\right)$ - conventional materials can be used, high density $(1450 \mathrm{~kg} / \mathrm{m} 3)$ and can be used an oxidizer in bipropellant and pure as a mono prop (dual-mode system). Recent space developments are implementing several simpler and less expensive rocket technologies. Aside from the facts stated above, $\mathrm{H}_{2} \mathrm{O}_{2}$ is a promising candidate for the future of green propellants due to its flexibility. To summarize, the benign nature of $\mathrm{H}_{2} \mathrm{O}_{2}$ allows for the advancement of simple, costeffective, and environmentally friendly propulsion with sufficient performance to replace hydrazine or other high-performing toxic propellants.

\section{Properties of $\mathrm{H}_{2} \mathrm{O} 2$ [4]:}

- $\mathrm{H}_{2} \mathrm{O}_{2}$ is non-toxic, making the mission more costeffective in the long run. Toxic propellants necessitate the use of additional safety precautions and procedures at an additional expense.

- It is not a cryogenic propellant, so no need for support devices like thermal control units to maintain cryogenic temperatures that add extra mass to the spacecraft.

- Simple thruster design that in small spacecraft is very helpful and highly desirable.

- In the stage of decomposition (in which thrust generates), hot gasses are produced mostly containing environmentally friendly water molecules.

- In nature, low volatility.

- Greater propulsionefficiency.

- High expansion to its initial value during decomposition (volume expansion exceeds 4500 times under normal conditions) which is favorable in nozzles.

- Highly stable and storable liquid.

- Can be used as a monopropellant and as well as bipropellant oxidizer.

- It has low vapor pressure (at room temperature about 2 $\mathrm{mm} \mathrm{Hg}$ ), it can be handled relatively easily.

\section{BI-PROPELLANT SYSTEMS}

The demand for better performance properties such as higher thrust increased specific impulse, and/or increased velocity gain no longer drives the production of rocket propulsion systems. Instead, criteria, which were historically known as secondary, are becoming increasingly prominent [5,6]. These include, among other things, a free and flexible thrust variation capability, easy handling and storage characteristics, low toxicity and health hazard risks for both propellant and exhaust flow species, improved handling and use protection, environmental friendliness, reusability, and strategies for upgrading and decommissioning under the aspects. Furthermore, mission scenarios are becoming increasingly complex, and current propulsion systems using traditional propellants are unable to meet all the anticipated mission requirements.

The propellant is stored in tanks outside the combustion chamber in liquid-propellant systems. The majority of these engines use a liquid oxidizer and liquid fuel, both of which are pumped from their respective tanks. The pumps boost the pressure above the engine's operating pressure, and the propellants are then pumped into the engine in such a way that the propellants are atomized and combined rapidly. Liquid-propellant engines have a range of benefits over solid-fuel engines in a variety of applications.

These features include (1) higher attainable effective exhaust velocities $(\mathrm{Ve}),(2)$ higher mass fractions (propellant mass divided by the mass of inert components), and (3) control of operating level in flight (throttle ability), sometimes including stop-and-restart capability and emergency shutdown. The engine, fuel tanks, and vehicle structure that hold these parts in place and connect to the payload and launchpad are typical components of a liquid-rocket propulsion system (or vehicle). Since they run at low pressure, fuel and oxidizer tanks are typically made of very light materials.

Bipropellant systems, in which an oxidizer and a fuel are tanked separately and combined in the combustion chamber, are used in most liquid-propellant rockets. Low molecular mass and high temperature of reaction products (for high exhaust velocity), high density (to reduce tank weight), low danger factor (e.g., corrosivity and toxicity), low environmental effect, and low cost are all attractive properties for propellant combinations. Tradeoffs are used to make decisions based on the applications.

\section{Properties of Liquid Methane $\left(\mathrm{CH}_{4}(\mathrm{~L})\right)$ :}

The fact that liquid fuels are easy to transport and handle is one of their most common characteristics. Liquid fuels' physical properties differ with temperature, but not as much as gaseous fuels. The flashpoint is the lowest temperature at which a flammable concentration of vapor is produced; the fire point is the lowest temperature at which a continuous burning of vapor occurs; the cloud point for diesel fuels is the lowest temperature at which dissolved waxy compounds begin to coalesce, and the pour point is the lowest temperature at which the fuel is too thick to pour freely. These characteristics have an effect on the fuel's safety and handling.

'Methane', a colorless and odorless hydrocarbon with the chemical formula $\mathrm{CH} 4$, is the simplest alkane which, due to its relative abundance, has become an economically attractive fuel and is the main constituent of natural gas. It is also referred to by other names like natural gas, marsh gas, carbon tetrahydride and hydrogen carbide $[7,8,9]$. When methane is burned, it undergoes the following reaction: $\mathbf{C H}_{4}+\mathbf{2} \mathbf{O}_{2} \rightarrow \mathbf{C O}_{2}+\mathbf{2} \mathbf{H}_{2} \mathrm{O}$. This is also known as combustion reaction. Methane on combustion emits $\mathrm{CO}_{2}$, Water vapor. Compared to other hydrocarbon fuels, methane produces less carbon dioxide for each unit of heat released $(891 \mathrm{~kJ} / \mathrm{mol})$. Liquified natural gas $(\mathrm{LNG})$ is methane liquified for ease of storage and is considered to have an energy content of 39 mega joules per cubic meter [7]. As a rocket fuel, methane is the only considered alternative hydrocarbon fuel till date along with Kerosene / RP1 as its competitor. The acquisition cost of methane is about three times smaller than for kerosene, and long-term availability is forecasted to be considerably higher $[10,11,12]$. 
The other advantages of methane in comparison to kerosene include higher specific impulse, lower pressure drop in cooling channels, superior cooling properties, higher coking limits, and less soot deposition. Besides, the combustion by-products of methane are only $\mathrm{CO}_{2}$ and $\mathrm{H}_{2} \mathrm{O}$ which are considerably smaller and greener than other fuels and moreover, methane is also best suited as a fuel in context of reusability $[13,14]$.

Despite the existence of several other hydrocarbons which can potentially be used as fuels, methane has been the prime focus for quite a bit of time not only for its reduced emissions, cost of acquisition, operational efficiency, and other features but for one more compelling purpose i.e., Mars. Planet mars has got a lot of prominence as the ideal place for planetary colonization and making humans multi-planetary species. Methane can be generated locally on mars through Sabatier reaction, this is known as In-situ methane production, and this is one of the leading factors for supremacy of methane over other hydrocarbon fuels in recent times.

\section{Stoichiometric Mixture Ratio Calculation}

Oxidation with liquid hydrogen peroxide ( $\mathrm{H} 2 \mathrm{O} 2)$

$$
\mathrm{CH}_{4}+4 \mathrm{H}_{2} \mathrm{O}_{2} \rightarrow \mathrm{CO}_{2}+6 \mathrm{H}_{2} \mathrm{O}
$$

Therefore, molecular weight of $\mathrm{CH}_{4}=1 * 12+4 * 1=16 \mathrm{amu}$

Molecular weight of $\mathrm{H}_{2} \mathrm{O}_{2}=2 * 1+16 * 2=34 \mathrm{amu}$

Stoichiometric O/F ratio of Liquid Methane $=(4 * 34) / 16=\mathbf{8 . 5}$

\section{METHOGOLOGY}

The major objective of this paper is to investigate green propellant fuel combustion characteristics. In the first section, it is focused primarily on the use and characteristics of hydrogen peroxide and on managing the space propulsion, but later on other hydrogen peroxide combination with liquid methane at different compositions with a NASA CEA code were investigated. This study is primarily executed to identify the effective bi-propellant combination to an appropriate $\mathrm{O} / \mathrm{F}$ ratio. This is evaluated in terms of combustion temperatures and specific impulse at various $\mathrm{O} / \mathrm{F}$ ratios of 2,4,6,8,10 with varied values for the 20, 25 and 30 bar of chamber pressure. Moreover, the concentration effect of the hydrogen peroxide has been investigated in terms of propulsion factors Further, using data which is driven from the CEA code is extracted and analyzed.

The CEA has been developed by Dr S. Gordon, Dr. B. J. McBride, and NASA colleagues at the Glenn Research Centre, for the computation of chemical equilibrium. The data library comprises a thermodynamic database and the software PAC99, which regresses and estimates thermodynamic data etc. Furthermore, CEA analysis is performed as discussed earlier and the here below the initial conditions given for have been tabulated.

Table 1: Initial Conditions

\begin{tabular}{|l|l|l|l|}
\hline S/N & Conditions & Unit & Value \\
\hline 1 & Low pressure & bar & 20 \\
\hline 2 & High pressure & bar & 30 \\
\hline 3 & Pressure interval & bar & 5 \\
\hline 4 & O/F ratio & N/A & $2,4,6,8,10$ \\
\hline 5 & The temperature of the fuel & K & 298.16 \\
\hline 6 & $\begin{array}{l}\text { Chamber pressure/ Exit } \\
\text { pressure }\end{array}$ & N/A & 30 \\
\hline
\end{tabular}

\section{RESULTS AND DISCUSSION}

\section{Pure Hydrogen Peroxide (liquid) as the oxidizer}

\section{A. Combustion Chamber}

\section{A.1. O/F ratio effect on the combustion temperature}

As the $\mathrm{O} / \mathrm{F}$ ratio increases, the combustion temperature Tc rises dramatically, peaking at $2850.25 \mathrm{~K}$ at $\mathrm{O} / \mathrm{F}$ ratio 8 and then decreasing slightly after that, as seen in Figure 1. As a result, the highest combustion temperature is said to be at the stoichiometric ratio. Further, if the fuel volume increased, the average combustion temperature does not have a significant this is due to adding more fuel than the stoichiometric ratio enables the production of partly oxidized products like $\mathrm{CO}$, which release less energy than the products of full combustion.

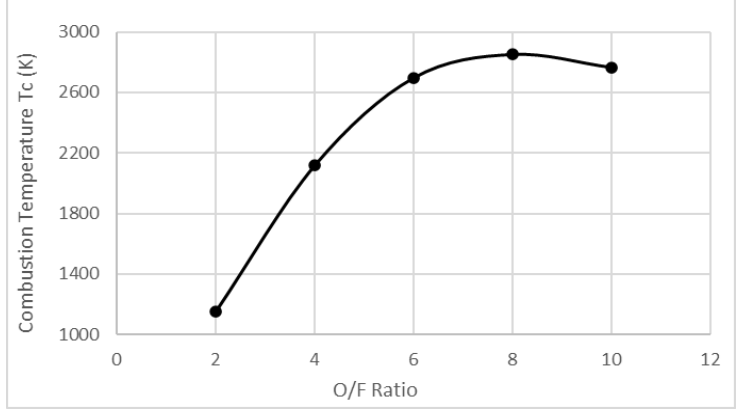

Figure 1: Variation of Combustion Temperature values for Liquid Methane at various $O / F$ ratios at a fixed chamber pressure 25 bar 


\section{A.2 Chamber pressure effect on the combustion temperature}

This section investigates the effect of the combustion chamber pressure on the chamber temperature for the Methane $/ \mathrm{H}_{2} \mathrm{O}_{2}$. Moreover, pure hydrogen peroxide is used as the oxidizer at the same initial conditions. Results were seen in terms depicted in Figure 2.

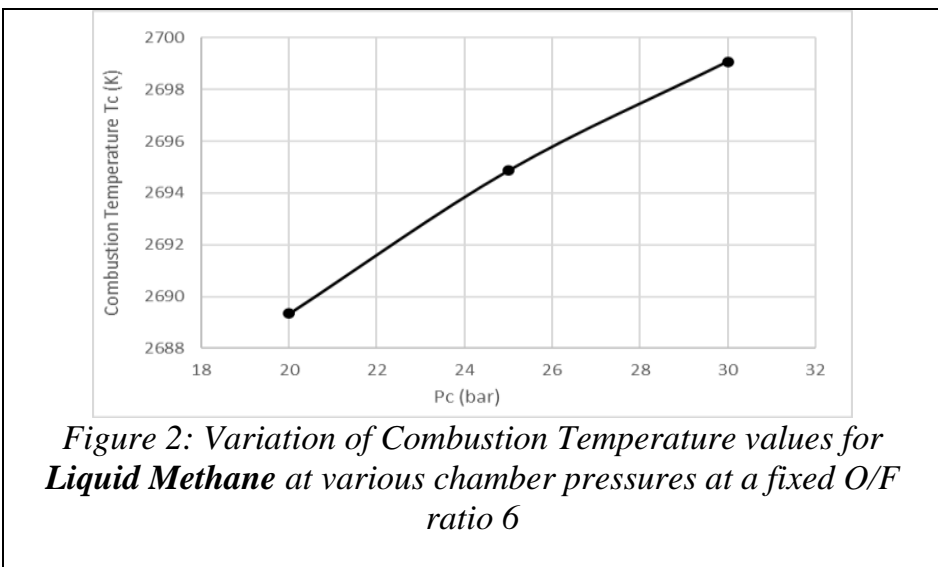

As the chamber pressure is raised, the combustion temperature increases as well, as seen in Table and Figure 2. This happens since, at such high temperatures, the combustion products behave like an ideal fluid, and it is a characteristic function of an ideal gas to see an increase in temperature with an increase in pressure.

\section{B. Specific Impulse}

\section{B.1 O/F ratio effect on the specific impulse}

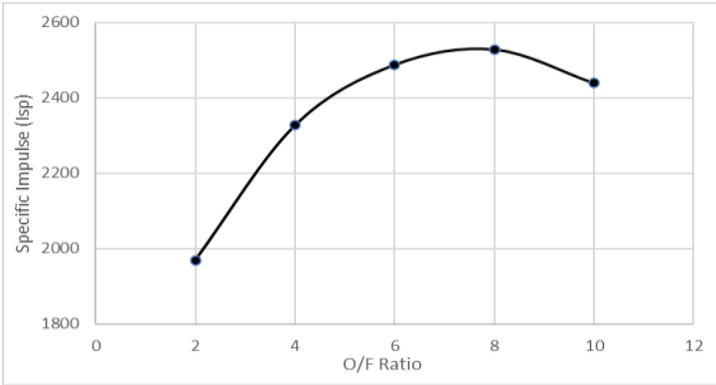

Figure 3: Variation of Specific Impulse values for Liquid Methane at various $O / F$ ratios at a fixed chamber pressure 25 bar

The Figure 3 depicts the trend of the specific impulse with respect to the variation of the oxidation to fuel ratio. It is seen that at $\mathrm{O} / \mathrm{F} 2$ there is a steady increase in the trend till 8 and followed by a decreasing trend till 10 . Further, having the highest specific impulse 2528.5 at the $\mathrm{O} / \mathrm{F}$ ratio of 4.

\section{B.2 Chamber pressure effect on the specific impulse}

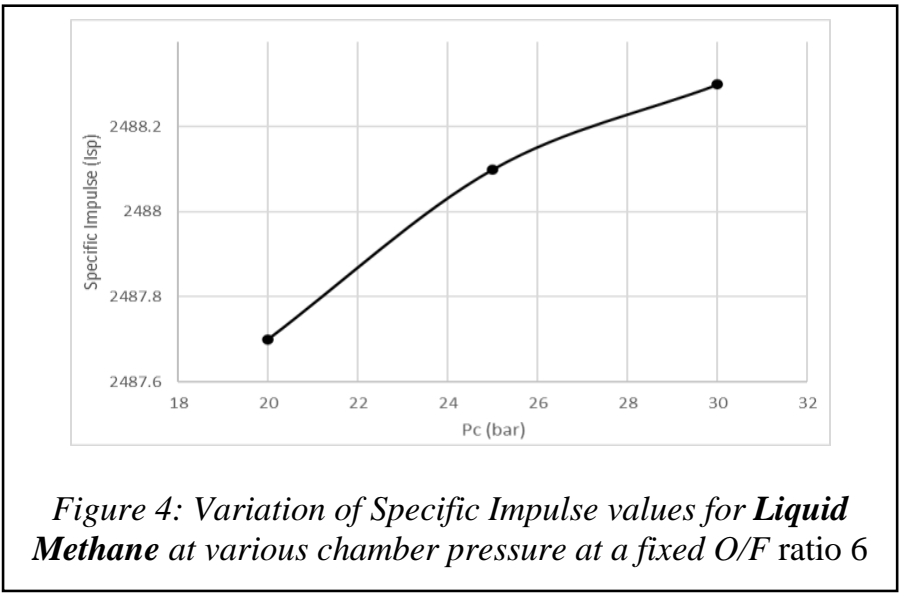

The Figure 4 shows the variation of specific impulse (Isp) changes in relation to rising in combustion chamber pressure for methane at oxidizer to fuel ratio 6 . Further, the specific impulse increases as the chamber pressure increases. This is since, at such high temperatures, the combustion products behave like ideal fluid, as described in the previous section. As a result, as the chamber pressure rises, the specific impulse rises as well.

Change in concentration Hydrogen Peroxide (liquid) as the $\underline{\text { Oxidizer }}$ 
This section would look at the difference of results by adding $10 \% \mathrm{H}_{2} \mathrm{O}$ to $90 \% \mathrm{H}_{2} \mathrm{O}_{2}$ for liquid methane and $98 \% \mathrm{H}_{2} \mathrm{O}_{2}$ with different $\mathrm{O} / \mathrm{F}$ ratios. Furthermore, it is considered at room temperature, the enthalpy of $\mathrm{H}_{2} \mathrm{O}$ is used as the default value for the CEA code.

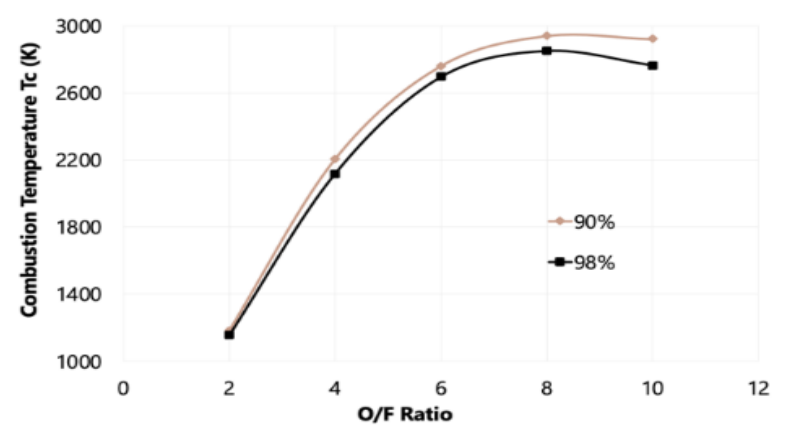

Figure 5: Variation of Combustion Temperature values for Liquid Methane at different O/F ratios for $90 \%$ and $98 \%$ $\mathrm{H}_{2} \mathrm{O}_{2}$

The graph above depicts the effect of the oxidizer fuel ratio on the temperature of the combustion chamber by using 90 and 98 percent hydrogen peroxide with methane. The combustion chamber increased until it reached 8 and hit a plateau after that. Furthermore, when the oxidizer fuel ratio is 8 , the temperature reaches a limit of $2939.36^{\circ} \mathrm{C}$ for $90 \% \mathrm{H}_{2} \mathrm{O}_{2}$. Using hydrogen peroxide as the pure oxidizer fuel ratio, on the other hand, a combustion temperature of $2850.25^{\circ} \mathrm{C}$ was achieved.

From this, it is observed that at lower oxidizer to fuel ratio the concentration difference of hydrogen peroxide doesn't bring a performance change as it happens for higher $\mathrm{O} / \mathrm{F}$ ratio. Higher the concentrations of hydrogen peroxide lower the combustion temperature values at higher $\mathrm{O} / \mathrm{F}$ ratios.

\section{Specific Impulse}

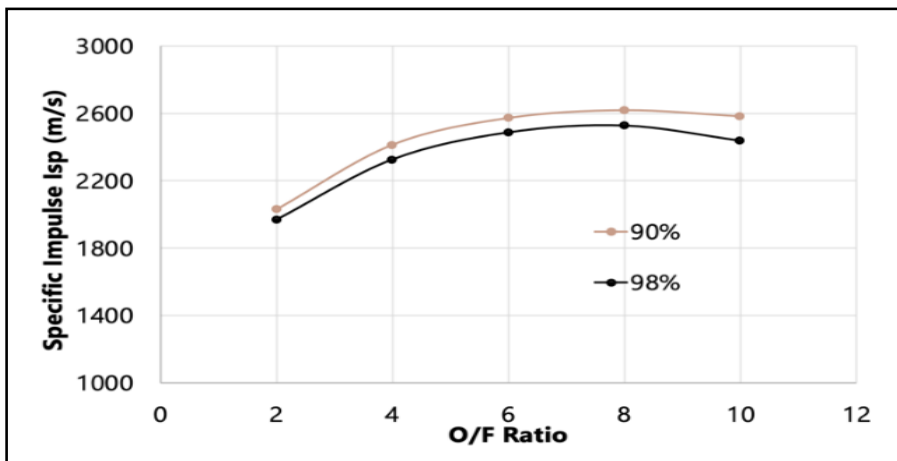

Figure 6: Variation of Specific Impulse values for Liquid Methane at different $\mathrm{O} / \mathrm{F}$ ratios for $90 \%$ and $98 \% \mathrm{H}_{2} \mathrm{O}_{2}$

The graph above evaluated the dependence of oxidation and fuel ratio on real impulse for a $90 \%$ and $98 \%$ hydrogen peroxide concentration at 25 bar combustion chamber pressure. The specific impulse initially increased significantly until 8 and then decreased slightly. At the stoichiometric ratio for $90 \% \mathrm{H}_{2} \mathrm{O}_{2}$, it is noted that the maximum real impulse is found to be 2618.7. It is observed that the concentration of hydrogen peroxide doesn't differ the performance as much even though it is higher when the concentration of $\mathrm{H}_{2} \mathrm{O}_{2}$ is less.

\section{Comparison of Combustion Products}

\section{Variation of Mass Fraction with respect to O/F Ratio}

This segment evaluates carbon monoxide and carbon dioxide emissions for Methane (L)/ Hydrogen Peroxide at a constant combustion chamber pressure of 25 bars.

Table 2: Mass Fraction values of $\mathrm{CO}$ and $\mathrm{CO}_{2}$ for Liquid Methane at various $\mathrm{O} / \mathrm{F}$ ratios at a fixed chamber pressure 25 bar

\begin{tabular}{|l|l|l|}
\hline O/F Ratio & \multicolumn{2}{|c|}{ Mass Fraction } \\
\hline & $\mathrm{CO}$ & $\mathrm{CO}_{2}$ \\
\hline 2 & 0.1142 & 0.388 \\
\hline 4 & 0.156 & 0.302 \\
\hline 6 & 0.091 & 0.248 \\
\hline 8 & 0.017 & 0.276 \\
\hline 10 & 0.00015 & 0.249 \\
\hline
\end{tabular}

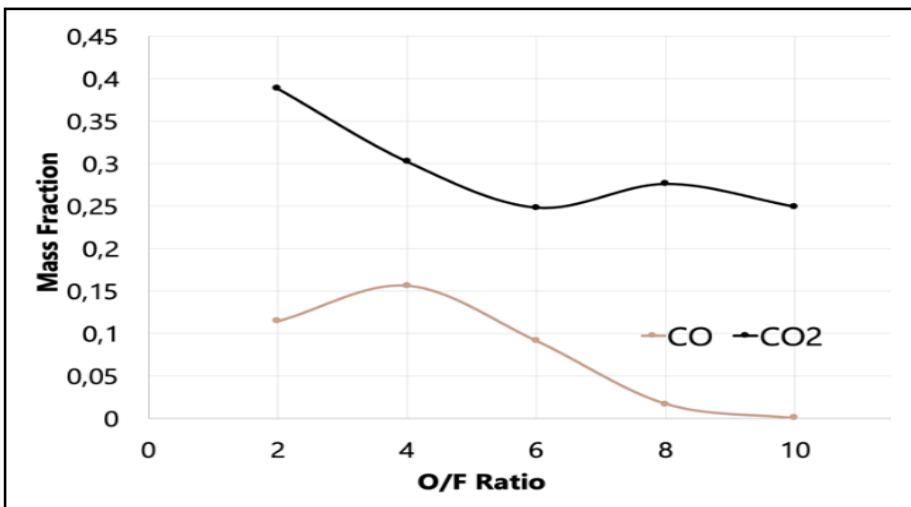

Figure 7: Variation of Mass Fraction values of $\mathrm{CO}$ and $\mathrm{CO}_{2}$ for Liquid Methane at various $O / F$ ratios at a fixed chamber pressure 25 bar

The mass fractions of carbon monoxide and carbon dioxide extracted in comparison to the oxidizer to fuel ratio are represented in the graph above.

Carbon dioxide is lowered when the oxidizer to fuel ratio is increased till $\mathrm{O} / \mathrm{F} 6$ and later has a slight fluctuation as the increase in oxidizer fuel ratio. Moreover, $\mathrm{CO}$ slowly increased until O/F 4, after which it eventually decreased. Finally, Carbon monoxide levels fell sharply as the oxidizer to fuel ratio improved. 
Variation of Mass Fraction with respect to Chamber, Throat and Exit

This section investigates the mass fractions of the decomposed species at chamber, throat and exit. Further, the analysis is done for Methane (L) as fuel at a fixed oxidizer fuel ratio of 4 and combustion chamber pressure at 25 bar.

Table 3: Mass Fraction values of $\mathrm{CO}$ and $\mathrm{CO}_{2}$ for Liquid Methane at chamber, throat and exit at a fixed chamber pressure 25 bar and $\mathrm{O} / \mathrm{F}$ ratio 8

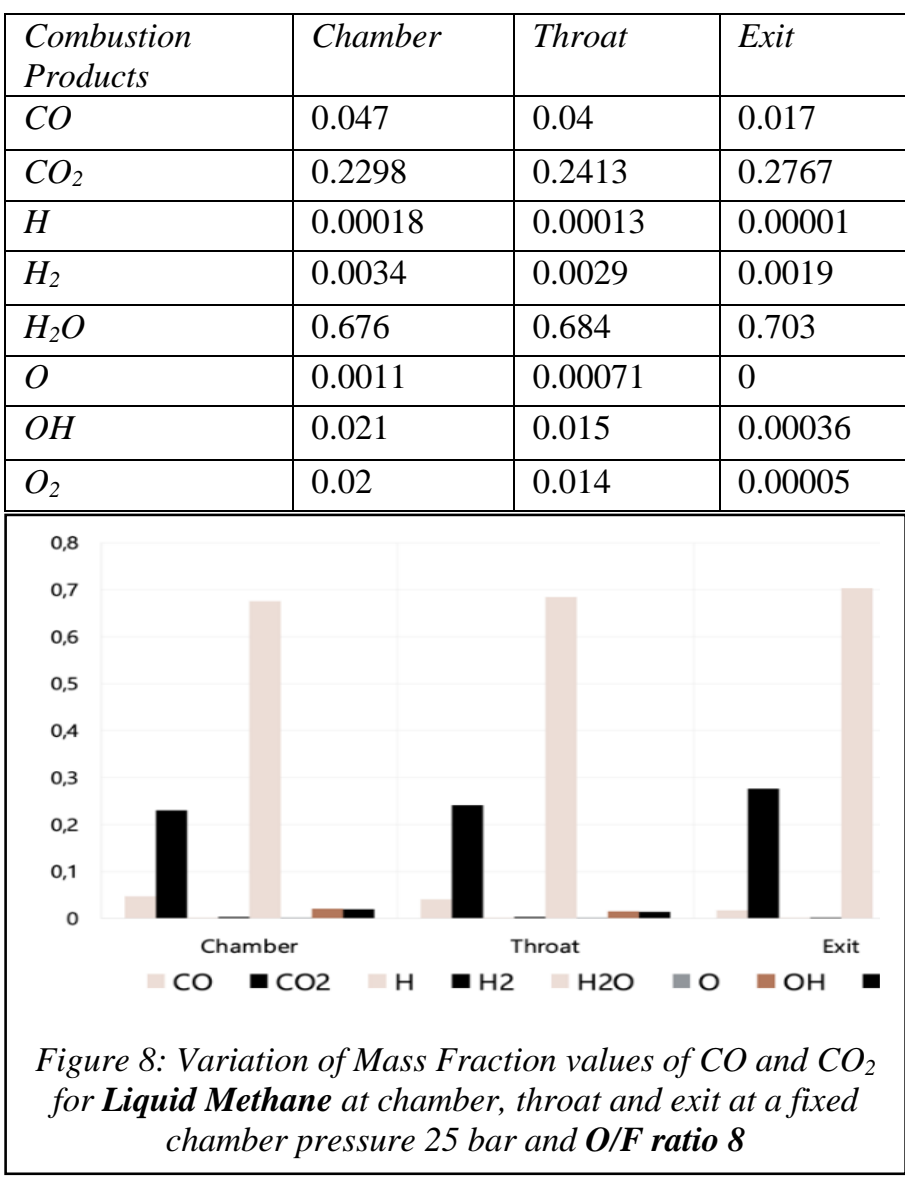

The above graph indicates the mass fraction of combustion products for Methane $(\mathrm{L}) /$ Hydrogen peroxide in chamber, throat, and exit at a constant combustion chamber pressure of 25 bar. Furthermore, since Methane(L) has the maximum temperature and specific impulse at this ratio, the oxidizer/fuel ratio of 6 was used in the analysis.

To begin, the combustion products show that $\mathrm{H}_{2} \mathrm{O}$ has the highest composition, followed by carbon dioxide and carbon monoxide, in that order. Second, though CO decreased gradually, mass fractions and the combustion chamber for $\mathrm{CO}_{2}$ increased steadily. As in the previous example, the mass fraction of combustion products such as $\mathrm{H}, \mathrm{H}_{2}$, and $\mathrm{O}$ is the least significant.

Comparison with Other Fuels : RP1, Ethanol and Liquid Methane
Pure Hydrogen Peroxide (liquid) as the Oxidizer

\section{Combustion Temperature -}

This section is assigned to analyze the hydrogen peroxide $\left(\mathrm{H}_{2} \mathrm{O}_{2}\right)$ liquid as the oxidizer with the Ethanol, RP-1, Liquid Methane.

Table 4. Mass Fraction values of $\mathrm{CO}$ and $\mathrm{CO}_{2}$ for Liquid Methane at various $\mathrm{O} / \mathrm{F}$ ratios at a fixed chamber pressure 25 bar

\begin{tabular}{|l|l|l|l|}
\hline$O / F$ & \multicolumn{3}{|l|}{ Combustion Temperature Tc $(K)$} \\
\hline & Ethanol & RP-1 & Methane(L) \\
\hline 2 & 2743.62 & 1336.31 & 1153.62 \\
\hline 4 & 3031.81 & 2541.57 & 2117.3 \\
\hline 6 & 2856.18 & 2915.51 & 2694.87 \\
\hline 8 & 2650.23 & 2865.17 & 2850.28 \\
\hline 10 & 2473.17 & 2725.53 & 2764.48 \\
\hline
\end{tabular}

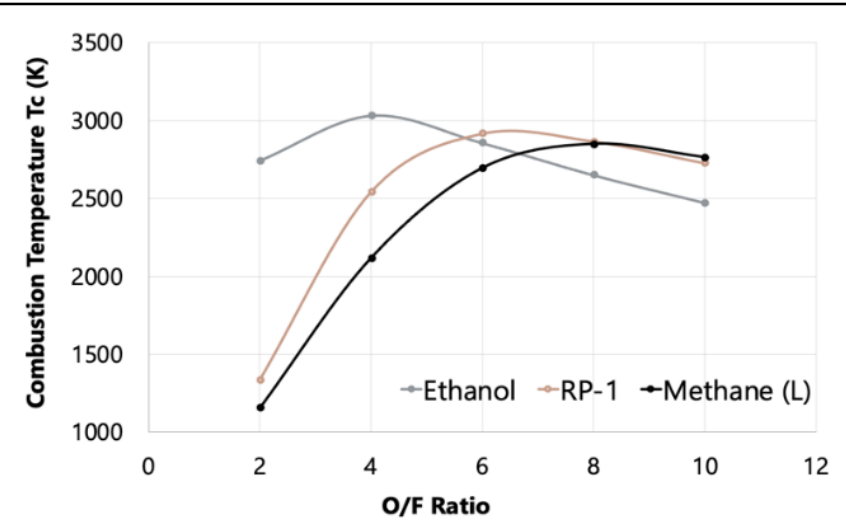

Figure 9: Variation of Combustion Temperature values for three fuels at various $O / F$ ratios at a fixed chamber pressure of 25 bar

The above graph depicts the effect of oxidizer to fuel ratio on the combustion chamber temperature for three different fuels (Ethanol, RP-1, Methane(L)) with pure hydrogen peroxide as the oxidizer fuel ratio at a fixed chamber pressure of 25 bars. Firstly, it is observed that the combustion temperature increased significantly till the stoichiometric ratio and then decreased substantially for the Ethanol and steadily for the other two fuels. Secondly, three fuels exhibited high temperatures at different oxidizer fuel ratios. Such as 4,6,8 oxidizer fuel ratios for Ethanol, RP-1, Methane(L) respectively. Interestingly, RP-1 and Methane (L) have lower temperatures at the fuel-rich mixtures when comparing with Ethanol. Furthermore, the highest temperature 3031.81 is achieved for hydrogen peroxide as an oxidizer with Ethanol at oxidizer fuel ratio 4 but we can observe that liquid methane performance increases with increase in $\mathrm{O} / \mathrm{F}$ ratio and there won't be any significant decrease as ethanol decreases.

Specific Impulse - 
Table 5: Specific Impulse values for three fuels at various $\mathrm{O} / \mathrm{F}$ ratios at a fixed chamber pressure of $25 \mathrm{bar}$

\begin{tabular}{|l|l|l|l|}
\hline O/F & \multicolumn{3}{|l|}{ Specific Impulse (Isp) } \\
\hline & Ethanol & Rp-1 & Methane (L) \\
\hline 2 & 2574.5 & 1963.1 & 1969.3 \\
\hline 4 & 2602.7 & 2380.7 & 2327.4 \\
\hline 6 & 2446.2 & 2492.5 & 2488.1 \\
\hline 8 & 2306 & 2445.4 & 2528.5 \\
\hline 10 & 2200.1 & 2340 & 2438.7 \\
\hline
\end{tabular}

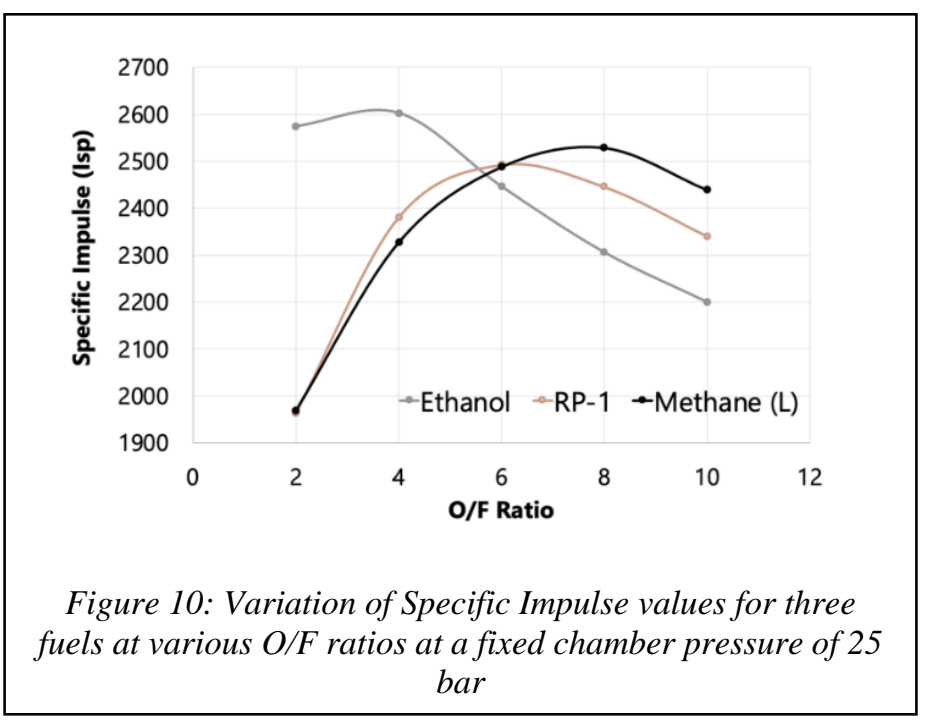

The above graph depicts the effect of oxidizer to fuel ratio on the specific impulse for three different fuels (Ethanol, RP-1, Methane(L)) with pure hydrogen peroxide as the oxidizer fuel ratio at a fixed chamber pressure of 25 bars. To begin with, the specific impulse rose dramatically before the stoichiometric ratio was reached, after which it decreased significantly for Ethanol and gradually for the other two fuels. Second, at various oxidizer fuel ratios, three fuels showed high specific impulses. In the illustration, the oxidizer fuel ratios for Ethanol, RP-1, and Methane(L) are 4,6,8 respectively have the highest specific impulses.

As compared to Ethanol, RP-1 and Methane (L) have lower temperatures at the fuel-rich mixtures. Furthermore, using hydrogen peroxide as an oxidizer with Ethanol at oxidizer fuel ratio 4 results in the maximum specific impulse of 2602.7 but the specific impulse for liquid methane increases with increase in $\mathrm{O} / \mathrm{F}$ ratio and it won't decrease significantly later which is an advantage.

\section{CONCLUSION AND FUTURE SCOPE}

Green propellants used for satellite-level propulsion systems have become attractive in recent years because of the non-toxicity and lower requirements of safety protection. According to the above analysis, hydrogen peroxide becomes more stable with higher peroxide content. Higher concentration of hydrogen peroxide resulted in lower temperatures in the variation of $\mathrm{O} / \mathrm{F}$ ratios. It is also observed that the as the concentration of hydrogen peroxide decreases, there is a small amount of the increase in specific impulse is observed. Increase in chamber pressure increases the chamber temperature and has a little effect on the specific impulse. The chamber temperature and the specific impulse, among other ratios, have the maximum values at the stoichiometric ratio. From the comparison studies, it is noted that the carbon dioxide and carbon mono oxide reduced qualitatively as there is an increase in oxidizer to fuel ratio. Furthermore, $\mathrm{H}_{2} \mathrm{O}$ has the highest composition of the combustion products, followed by carbon dioxide and carbon monoxide in that order. Second, though $\mathrm{CO}$ levels rapidly declined, mass fractions for $\mathrm{CO}_{2}$ are steady. The mass fraction of combustion products such as $\mathrm{H}, \mathrm{H} 2$, and $\mathrm{O}$ is the least important.

To conclude from these case studies we have performed, it is easily notable that hydrogen peroxide outweighs ither propellants in terms of toxicity, cost and performance. It will be a promising propellant in the near future as it has a low emission of toxic combustion products. Future of space exploration is likely to include many fascinating means of propulsion for the purpose of space exploration or viable solutions to reach orbit with minimal environmental impact.

\section{ACKNOWLEDGMENT}

"Great things are not done by one person. They're done by a team of people." - Steve Jobs

This paper becomes a reality with the kind support and help of many individuals. we would like to extend our sincere thanks to all of them.

Foremost, we want to offer this endeavor to our GOD Almighty for the wisdom he bestowed upon us, the strength, peace of mind and good health to finish this research. Furthermore, we would like to thank our families and friends without whose support and encouragement this would have been impossible for us to undertake

\section{REFERENCES}

[1] Haeseler, D. \& Bombelli, V. \& Vuillermoz, P. \& Lo, R. \& Marée, T. \& Caramelli, Fabio., "Green Propellant Propulsion Comncepts for Space Transportation and Technology Development Needs", 557. 4. 2007.

[2] Robert Masse et al.: M315E "Propulsion System Advances and Improvements", AIAA 4577- 2016.

[3] FJ.Dyer et al.: "First Implementation of High-Performance Green Propulsion in a Constellation of Small Satellites", SSC13-VII -2.

[4] Angelo Cervone, Graham T. Roberts et al., "Development of Hydrogen Peroxide Monopropellant Rockets", American Institute of Aeronautics and Astronautics.

[5] Sackheim, R.L., amd R.K. Masse. "Green Propulsion AdvancementChallenging the Maturity of Monopropellant Hydrazine". In $49^{\text {th }}$ AIAA Joint Propulsion Conference. San Jose, CA, USA; 2013.

[6] Ciezki, H.K., M. Negri, and L. Werling., "Trends in Research and Development on Green Chemical Propulsion for Orbital Systems". In: $7^{\text {th }}$ Int. Conference on Recent Advances in Space Technologies, Istanbul, Turkley; RAST 2015. 16-19 June 2015. 
[7] Safety Data Sheet - Material Name: Gasoline All Grades, SDS No. 9950, Hess Corporation, Aug. 2012.

[8] Materials Safety Data Sheet (MSDS) Ethanol (C2H5OH), MSDS Number NCP/P/1, NCP Alcohols, Aug.2018.

[9] Safety Data Sheet - Material Name: kerosene K1 and K2, SDS No. 0290, Hess Corporation, Aug. 2012.

[10] CAMEO Chemicals, Gasoline [Online]. Available: https://cameochemicals.noaa.gov/chemical/11498 (Accessed : 26/10/2019).

[11] CAMEO Chemicals, Ethanol [Online]. Available: https://cameochemicals.noaa.gov/chemical/667 (Accessed : 26/10/2019)

[12] CAMEO Chemicals, Kerosene [Online]. Available: https://cameochemicals.noaa.gov/chemical/960 (Accessed : 26/10/2019).

[13] Safety Data Sheet - Material Name: Jet Fuel JP5, SDS No. 9942, Hess Corporation, Aug. 2012.

[14] CAMEO Chemicals, Methane, Refrigerated liquid (Cryogenic Liquid) [Online]. Available: https://cameochemicals.noaa.gov/chemical/3872 (Accessed : 26/10/2019).

\section{AUTHORS}

First Author - Srilochan Gorakula, Masters in Aeronautical Engineering, Politecnico di Milano, srilochan.gorakula@mail.polimi.it

Second Author - Mary Sharon Rose Bondugula, Masters in Space Engineering, Politecnico di Milano,

marysharon.bondugula@mail.polimi.it

Third Author - Samarth Patel, Masters is Aerospace Engineering, IIAEM, Jain (Deemed-to-be University), samarth1998.sp@gmail.com

Fourth Author - Aasha Inapanury, Masters is Aerospace Engineering, Alma mater Studiorum - Universita di Bologna aasha.inapanury@studio.unibo.it

Correspondence Author - Samarth Patel, Masters is Aerospace Engineering, IIAEM, Jain (Deemed-to-be University), samarth1998.sp@gmail.com 